\author{
Stella Maris Scatena Franco
}

Universidade Federal de São Paulo (Guarulhos)

\title{
Uma dama argentina em terras yankees: os Recuerdos de viaje, de Eduarda Mansilla
}

Resumo: Neste artigo analiso o relato de viagem da escritora argentina Eduarda Mansilla aos Estados Unidos, intitulado Recuerdos de viaje (1882). Integrante de uma camada social privilegiada e oriunda de uma família tradicional pertencente à elite política argentina, a autora expõe um ponto de vista particular sobre as condutas das norte-americanas com quem conviveu em sua viagem, mostrando com isso sua própria concepção sobre os papéis sociais femininos.

Palavras-chave: relatos de viagem; mulheres; Eduarda Mansilla.

Copyright (c) 2008 by Revista Estudos Feministas.

\section{Introdução}

O século XIX foi um momento de farta produção de relatos de viagens, tendo eles sido redigidos, a despeito do que se imagina, não apenas por homens, mas também por mulheres viajantes. Trata-se de um período marcado pelo desenvolvimento de tecnologias que impulsionaram os transportes marítimos, um dos fatores que contribuíram para intensificar o fluxo de viajantes entre diferentes continentes. Além disso, ainda que tenham sido mais comuns os deslocamentos de europeus para diferentes partes do mundo, indivíduos das chamadas áreas 'periféricas' também realizaram suas viagens, produzindo textos nos quais narraram suas experiências de viagem. Recuerdos de viaje (1882), da argentina Eduarda Mansilla, ilustra bem essa situação não propriamente comum ou típica, ainda que fosse cada vez mais largamente possível no século em questão: uma mulher escritora oriunda de um país latino-americano viajando pelo aclamado 'mundo civilizado' (neste caso, os Estados Unidos), descrevendo suas experiências e emitindo suas apreciações. 
' Para o seu olhar sobre os Estados Unidos remeto ao capítulo IV de livro de minha autoria: Stella Maris Scatena FRANCO, 2008.

${ }^{2}$ A autora era filha de Agustina Ortiz de Rozas, irmã mais nova de Juan Manuel de Rosas, que entre 1829 e 1852 governou a província de Buenos Aires, com amplos poderes sobre toda a Argentina, sob o signo do federalismo. Seu pai, o General Lucio Norberto Mansilla, teve uma prolongada carreira militar e política. Dentre outras atuações, participou da defesa de Buenos Aires contra as invasões inglesas de 1806 e 1807; integrou o Exército dos Andes, organizado pelo General José de San Martín, e participou de importantes batalhas que contribuíram para a independência do Chile, como as de Chacabuco (1817) e Maipú (1818); foi governador da província de Entre Ríos entre 1821 e 1824 e apoiou, em 1826 , a constituição do governo unitário de Bernardino Rivadavia. Ocupou cargo de chefe de polícia de Buenos Aires entre 1833 e 1835 , foi membro da legislatura de Buenos Aires entre 1840 e 1844 e lutou contra os ingleses e os franceses na Batalha de Obligado, em 1845. Em 1852, ocupou função de comandante da cidade de Buenos Aires. Após a queda de Rosas, o General Mansilla exilouse em Paris e foi colocado politicamente no ostracismo. No rol de personalidades da família de Eduarda Mansilla se destacava também seu irmão, Lucio $V$. Mansilla, escritor da chamada 'Geração de 1880', periodista, político, inveterado viajante e autor de Una excursión a los indios ranqueles (para dados biográficos de Eduarda e informações sobre seu meio familiar, baseei-me sobretudo nos textos memorialísticos de seu irmão Lucio e seu filho Daniel: Lucio V. MANSILLA, 1978; e Daniel GARCÍA-MANSILLA, 1950).

${ }^{3}$ Segundo o filho de Eduarda, Daniel García-Mansilla, o casamento de seus pais foi noticiado em um diário de Montevidéu como uma versão sul-
Diferentes temas são presentes no relato. Neste artigo, concentrar-me-ei na forma como Eduarda Mansilla descreveu as norte-americanas. ${ }^{1}$ Pelas críticas e pelos elogios que vai tecendo às norte-americanas das camadas abastadas, com quem conviveu nos Estados Unidos, percebemos o que pensava sobre papéis sociais femininos, definidos de acordo com predeterminações culturais ou com a questão do pertencimento a grupos sociais específicos. Sendo uma mulher da elite argentina, devia mostrar-se como uma dama exemplar e respeitável, condenando ações que não correspondessem ao padrão de comportamento condizente com o das mulheres de sua condição social. Seu relato é, assim, uma demonstração de exemplos de condutas, normas e convenções que buscavam regular a vida social das mulheres de elite do século XIX. Porém, como não há norma que resista, sempre, intacta, é possível perceber pelo próprio relato que a autora, às vezes, também ultrapassou fronteiras, abordando temáticas supostamente 'proibidas' para 'elas'.

\section{Eduarda Mansilla}

A trajetória de Eduarda Mansilla (1838-1892) e de sua família está intimamente ligada à história política da Argentina. ${ }^{2}$ Muito cedo, Mansilla aprendeu a falar o francês e com apenas doze anos teria servido de tradutora de Rosas nas negociações diplomáticas entre França e Buenos Aires durante o governo de seu tio. A propósito de sua formação, obteve a educação elementar em escola particular e depois disso começou a receber preceptores em sua casa, sendo também acompanhada, em seus estudos, pela mãe.

Apesar da ligação familiar com o federalismo, Eduarda casou-se, em 1855, com 17 anos, com o advogado, político e diplomata Manuel Rafael García, partidário dos unitários, tradicionalmente rivais à política federalista de Rosas. ${ }^{3}$ Manuel R. García, nascido em 1826, era de família criolla e abastada, que também manteve íntimas relações com o poder na Argentina. ${ }^{4}$ Realizou sua formação escolar em Buenos Aires, no Colégio Santo Ignácio, de jesuítas, e depois se formou advogado; entretanto, como o pai, seguiria posteriormente a carreira diplomática. ${ }^{5} \mathrm{Na}$ década de 1840 , como bom jovem de família abastada, partiu para a Europa, onde viajou para a Espanha - para conhecer parte da família que lá vivia " e para Paris - para aperfeiçoar o idioma francês. De volta a Buenos Aires, entrou para a política e tornou-se deputado, em 1856. Em 1861, iniciou sua carreira diplomática, que o levaria a passar o resto da vida entre a Europa e os Estados Unidos. Eduarda Mansilla o acompanhou em grande parte de suas viagens, vivendo na 
americana de Romeu e Julieta (GARCÍA-MANSILLA, 1950, p. 22). ${ }^{4} \mathrm{O}$ primeiro espanhol do ramo de sua família na América foi seu avô paterno, o coronel Pedro Andrés García, que chegou a Buenos Aires em 1776, com o primeiro Vice-Rei do Rio da Prata. Desenvolveu carreira militar em Buenos Aires e foi graduado coronel em 1909.

${ }^{5}$ Seu pai, o diplomata Manuel José García, foi ministro da Fazenda por três vezes e participou no início do governo Rosas, com quem logo se desentendeu.

${ }^{6}$ María Rosa LOJO, 2002, p. 225.

${ }^{7}$ Bonnie FREDERICK, 1994, p. 249.

${ }^{8}$ Lily SOSA DE NEWTON, 1994.

${ }^{9}$ Quando partiu da Argentina, em 1861, já tinha tido dois filhos "Eda (Eduarda) e Manuel ", que eram crianças à época da viagem. Todos os outros - Rafael, Daniel, Eduardo e Carlos " nasceram fora da Argentina. qualidade de "diplomática consorte" e e tendo, na acepção de alguns autores, uma "vida nômade".

O casamento deu à autora a oportunidade de viajar entre a Europa e os Estados Unidos. Em 1861, pouco antes do início da Guerra de Secessão, seu marido foi comissionado numa missão diplomática para estudar as características e o funcionamento do sistema judiciário norte-americano. A primeira permanência nos Estados Unidos durou até 1863 , quando seu marido foi designado, por Bartolomeu Mitre, então Presidente da Argentina, como primeiro-secretário de quatro legações argentinas na Europa: França, Inglaterra, Itália e Espanha. A família partiu, então, para a Europa. O casal retornaria ainda aos Estados Unidos, ali permanecendo entre 1868 e 1873. Manuel R. García havia sido indicado como ministro plenipotenciário naquele país, em substituição a Domingo F. Sarmiento, que estava nos Estados Unidos e retornara à Argentina para assumir a Presidência da República. ${ }^{8}$ Em 1873 o casal retornou à Europa em razão da ordem recebida por García, pelo governo de Sarmiento, de que se encaminhasse à Inglaterra para dirigir a construção da primeira frota de guerra moderna da Argentina, função que manteve paralelamente à de ministro plenipotenciário dos Estados Unidos. Eduarda se estabeleceu com os seis filhos em Paris, ${ }^{9}$ enquanto seu marido viveu entre esta cidade e Londres. Em 1875, sua única filha mulher, Eda, casou-se com um militar e nobre francês, o Barão Charles de Lagatinerie. Alguns anos depois, Eduarda Mansilla voltou para Buenos Aires com os dois filhos menores, deixando seu marido na Europa e os outros filhos sob os cuidados da filha, Eda.

Em meados da década de 1880 , tendo voltado à Europa, Eduarda Mansilla se instalou em Paris, enquanto seu marido foi transferido para Viena. Em 1886 residiu em Florença e em 1887 viajou para Viena com o objetivo de estar perto do marido, que se encontrava doente e que morreu nesse mesmo ano. Depois da morte de Manuel R. García, Eduarda seguiu com os filhos e o genro para Buenos Aires para resolver questões testamentárias. Voltou ainda a residir em Viena, onde um de seus filhos, Daniel García, exercia o cargo diplomático de segundo-secretário da legação Argentina, missão interrompida em 1890 por razões de corte no orçamento do governo argentino, o que determinou o retorno da família para Buenos Aires. Eduarda viveria mais dois anos em sua cidade natal, onde faleceu, em 1892, aos 54 anos de idade.

\section{Recuerdos de viaje}

Ao longo de suas viagens pela Europa e pelos Estados Unidos, Eduarda Mansilla cumpriu uma vasta 
${ }^{10} \mathrm{Na}$ França, primeiro apareceu como folhetim numa revista intitulada L'Artiste e em seguida em livro pela editora Lachaud. Em 1870, seu irmão Lucio V. Mansilla o traduziu para o espanhol - já que a primeira edição aparecera em francês, publicando em forma de folhetim o diário La Tribuna. Só recentemente foi publicado na Argentina em forma de livro: Eduarda MANSILLA, 1999.

1 As informações sobre suas publicações foram coletadas em: Néstor Tomás AUZA, 1999; SOSA DE NEWTON, 1994; e Mónica SZURMUK, 2000.

12 SOSA DE NEWTON, 1994, p. 92.

${ }^{13}$ María Gabriela MIZRAJE, 1999, p. 132. 'agenda diplomática' como acompanhante de seu marido. Nos Estados Unidos, por exemplo, participou de salões e festividades na Casa Branca, tendo mantido contato com o Presidente Abraham Lincoln, em sua primeira estada no país (1861-1863), e com o Presidente Ulysses Grant, na segunda fase de sua viagem (1868-1873). Na Europa, conheceu artistas como Alexandre Dumas (pai) e o compositor Antonio Rossini, além de manter contatos com a Imperatriz Eugenia, esposa de Napoleão III.

Apesar de ter produzido enquanto viajava, o grosso de sua obra foi publicado nos momentos em que esteve na Argentina. Seus dois primeiros romances, El médico de San Luis e Lucía Miranda, são de 1860, antes da primeira viagem para os Estados Unidos. Em seu retorno à Argentina, publicou Cuentos (literatura infantil, 1880), La Marquesa de Altamira (drama, 1881), Recuerdos de viaje (memórias, 1882), Creaciones (contos, 1883) e Un amor (romance, 1885). Porém, excepcionalmente, seu mais conhecido romance Pablo, ou la vie dans les Pampas foi publicado em Paris, em 1869. ${ }^{10}$ Além dessas obras, colaborou com artigos em periódicos portenhos. Escreveu sobre teatro na revista La Flor del Aire, que teve a meteórica duração de um mês, no ano de 1864; sobre música em El Alba, em 1868, e em La Gaceta Musical, entre 1879 e 1982; por fim, sobre moda em El Plata llustrado, publicação semanal que vigorou de 1871 a 1873. Também consta que, sendo aficionada pela música, compôs canções e foi crítica de ópera. ${ }^{11}$

Eduarda pertencia às camadas privilegiadas da Argentina, o que Ihe possibilitava certos luxos: quando morava nos Estados Unidos, importava de Paris roupas assinadas por renomados estilistas. Aliás, tinha conhecido de perto a Imperatriz dos Franceses, Eugenia de Montijo, considerada como modelo de elegância na corte imperial de Napoleão III. Vivia, assim, em um meio "en que la pompa y la ostentación eran asunto diario, y las reuniones y paseos, una obligación ineludible"..$^{2}$ Trata-se de uma personagem que, de acordo com Gabriela Mizraje, lembra-nos, a cada passo, "la explosión del nombre" e "el peso de la historia", pois a autora era "hija de Lucio N. Mansilla, hermana de Lucio V., sobrina de Rosas, esposa de Manuel R. García [...]". ${ }^{13}$

Em Recuerdos de viaje, Eduarda Mansilla narra suas viagens pelos Estados Unidos, e sua posição como mulher da elite se reflete nitidamente em seu relato, dedicado a descrever fatos da vida social e hábitos dos norteamericanos entre os quais conviveu. Seu relato é farto em observações sobre o comportamento das mulheres, sobretudo das camadas abastadas norte-americanas. Essas apreciações são particularmente interessantes, pois traduzem muito do que pensava a própria autora sobre as 
${ }^{14}$ MANSILLA, 1996. O livro foi publicado pela primeira vez em Buenos Aires, pela editora Juan A. Alsina, em 1882

${ }^{15}$ Mansilla aponta Bermúdez de Castro como autor da frase.

${ }^{16}$ MANSILLA, 1996, p. 7.

17 MANSILLA, 1996, p. 28

${ }^{18}$ MANSILLA, 1996, p. 41.

19 SZURMUK, 2000. condutas femininas e as idealizações das divisões de papéis entre os sexos. Antes de abordarmos essas questões, cabe apresentar em linhas gerais o relato.

Eduarda Mansilla viajou, como mulher de diplomata, entre os Estados Unidos e a Europa, mas retratou em seu relato sua permanência somente entre os norte-americanos. Lá esteve em diferentes temporadas: a primeira entre 1861 e 1863 e, depois, entre 1868 e 1873. Ainda que a vivência entre os europeus seja absolutamente marcante na trajetória da autora, teve a intenção primeira e central de retratar os Estados Unidos ao conceber os seus Recuerdos de viaje. ${ }^{14}$

É muito comum nos depararmos com relatos escritos em forma de diário, configurando-se como registros quase cotidianos de excursões realizadas por seus autores no momento presente da viagem. De natureza diferente é o relato aqui em questão, como demonstra, logo de início o título " Recuerdos de viaje " e a epígrafe do livro - "Recordar es vivir". ${ }^{15}$ Trata-se de um livro de memórias escrito não pouco tempo depois da viagem, mas elaborado cerca de duas décadas após a tomada das primeiras impressões in loco. Por essa razão, o argentino Domingo Faustino Sarmiento, ao comentar, de forma elogiosa, o seu livro à época do lançamento, em 1882, afirmou: "Los Recuerdos de viaje no son los viajes mismos, sino lo que de ellos queda cuando ya estamos en casa". ${ }^{16}$ De fato, os Recuerdos, escritos tanto tempo depois da viagem, não são propriamente descrições, passo a passo, dos locais que a autora conheceu. O grande intervalo de tempo transcorrido entre a viagem e a escrita particulariza seu relato e é crucial para as especificidades que nele encontramos. Trata-se de um livro com um viés descritivo, mas ao mesmo tempo fortemente analítico. Como apontou Sarmiento, não se tratava de um diário, escrito sob o impacto das primeiras emoções, mas de um texto amadurecido e bastante elaborado. Em razão disso, a autora se posiciona como uma viajante experiente, como alguém que analisa o objeto abordado julgando possuir sobre ele um grande conhecimento. Por isso faz questão de deixar claro, por exemplo, ter "habitado la Metrópoli norte americana" ${ }^{17} \mathrm{e}$ "haber vivido [...] algunos años en los Estados Unidos". ${ }^{18}$ Além disso, do alto de sua experiência de mulher viajada, faz freqüentes comparações entre os Estados Unidos e a Europa e, em menor medida, a Argentina.

Esse livro foi projetado para ser o primeiro de uma série composta de outros relatos de viagem. Entretanto, assegura-se que esses outros relatos nunca foram escritos. ${ }^{19}$ Como primeiro tomo de uma série de relatos, reflete sobre o período da primeira estada nos Estados Unidos, entre 1861 e 1863. A segunda temporada (1868-1873) deveria ser 
${ }^{20}$ MANSILLA, 1996, p. 196.

21 SZURMUK, 2000.

22 MANSILLA, 1996.

${ }^{23}$ MANSILLA, 1996, p. 29.

${ }^{24}$ A autora usa a palavra "estudo" ou variações reiteradas vezes ao longo do texto (MANSILLA, 1996).

${ }^{25}$ SZURMUK, 2000, p. 11. narrada em outro volume: "En un segundo tomo contaré mis impresiones de esa vuelta á la triunfante Union Americana". ${ }^{20}$

Afirma-se que os Recuerdos foram escritos com base em diários íntimos, ${ }^{21}$ o que teria ajudado na ativação das lembranças. No entanto, como texto escrito muito tempo depois, sofreu reformulações, podendo-se observar que a autora oscila no tempo ao narrar acontecimentos posteriores à sua primeira temporada. Assim, chega a tecer um comentário relativo ao período de sua segunda temporada nos Estados Unidos, quando o país era governado pelo Presidente Ulisses S. Grant (1869-77). ${ }^{22}$ Também atualiza seu relato ao mostrar que muitas mudanças tecnológicas haviam ocorrido no espaço transcorrido entre a viagem e a escrita.

Além de ser um livro de memórias, o texto tem ainda outras particularidades. Ele se constitui como uma espécie de livro de crônicas de costumes, pelas quais a autora descreve e analisa os hábitos e os aspectos do cotidiano das famílias norte-americanas, de personalidades do mundo político e de pessoas pertencentes às altas rodas sociais que encontrava nas festas das quais participava como mulher de diplomata. Dentre os temas narrados estão ainda aqueles que poderíamos classificar como mais 'supérfluos', como a moda adotada pelas mulheres 'elegantes' norte-americanas, as formas de galanteio e os flertes nos bailes e nos acontecimentos sociais variados, além da decoração das casas. Mansilla considera que o viajante tem um olhar específico, ávido. Interessado em analisar e compreender o outro, ele "se vuelve todo ojos". ${ }^{23}$ Seu relato pretende ser um 'estudo' dos hábitos da sociedade norteamericana, sobretudo das mulheres norte-americanas. ${ }^{24}$

\section{Olhares cruzados}

Seu relato é farto em observações sobre o comportamento das mulheres das camadas abastadas norte-americanas, mas aquilo que seu olhar capta e sua pena registra também traduz muito da própria autora. Assim, ao mesmo tempo que olha para elas e sente-se olhada, descreve os costumes alheios e expõe seus próprios pontos de vista. Não se trata de uma visão unilateral, mas sim de 'olhares trocados'. Como afirma Mónica Szurmuk, os relatos das viajantes, além de exporem espaços pouco abordados pelos homens, como o interior das casas, por exemplo, têm "un eje de origen, la viajera, que al tiempo que es observada, se observa y se reconoce en su propio texto. [...] las mujeres se saben miradas y juzgadas. En los relatos de mujeres hay miradas cruzadas". ${ }^{25}$ Temos um exemplo dessa "troca de olhares' na descrição de uma festa na mansão de um banqueiro da Quinta Avenida, em Nova lorque. Mansilla 
${ }^{26}$ MANSILLA, 1996, p. 176.

${ }^{27}$ MANSILLA, 1996, p. 178.

${ }^{28}$ MANSILLA, 1996, p. 163-164.

${ }^{29}$ MANSILLA, 1996, p. 48.

${ }^{30}$ MANSILLA, 1996, p. 178. afirma ter se sentido devorada pelo olhar das jovens norteamericanas, que "interrumpian su charla para mirarme de arriba abajo". ${ }^{26}$

Eduarda perscruta ambientes e pessoas: expõe em minúcias os espaços e radiografa os comportamentos das jovens norte-americanas. Seu relato tenta ser cordial, mas um fundo ácido não deixa esconder a diferença que acredita haver entre ela e as norte-americanas. Isso transparece com certa freqüência pelo seguinte mecanismo: a autora intercala, numa descrição que se pretende neutra, forçados elogios e críticas irônicas. Faz questão de notar, por exemplo, que nas festas as jovens se vestiam sempre com roupas da última moda de Paris, observando, no entanto, um certo exagero nos tules e nas pedrarias, exagero que, para ela, "ocurre siempre en el exterior". ${ }^{27}$ Com isso quer mostrar-se uma legítima conhecedora da moda parisiense, diferentemente das norte-americanas, que julgava como pertencentes a uma espécie de grupo de 'novas ricas', sem carregarem o peso da tradição e a vivência européia que, ela, sim, possuía.

O mesmo se passa quando descreve uma jovem elegante em Saratoga. Sarcasticamente, faz o leitor atentar para a compleição física das norte-americanas, para ela excessivamente magras: "La bata era un fouilli de encajes angostos, rosas, brillantes sueltos y lazos de cinta que disimulaban, o mejor dicho, aumentaban lo que las realidades dejaran desear". ${ }^{28}$ Ainda aludindo à questão da estética corporal, mostra-se impressionada com a desproporção entre o apetite das norte-americanas e a manutenção de suas modestas silhuetas e não deixa de ironizar: "Esas mujeres que parecen vivir del aire como nuestras orquídeas del Paraná, conen y beben como héroes de Homero". ${ }^{29}$

Também podemos notar suas críticas quando mostra a fixação das norte-americanas pela Imperatriz Eugenia, esposa de Napoleão III, famosa pelo luxo e pelo brilho que levou à corte imperial francesa. Mansilla afirma que, apesar de as norte-americanas terem ricas jóias, aderiam de maneira excessiva às bijuterias para poderem copiar Eugenia, "la soberana que más joyas ha tenido en el mundo". ${ }^{30}$ Esse comportamento, segundo a autora, representava, no fim das contas, mais "inveja" e "desdém" do que "verdadeira admiração". Ainda afirma que essas jovens, ao imaginarem, em sonhos vãos, que podiam ter sido escolhidas, no lugar de Eugenia, por Napoleão III, desconsideravam o fato de a imperatriz ser "una dama encumbrada, de ilustre linaje y grandes vínculos sociales; sin olvidar ademas el prestigio soberano de la belleza, uno de los más poderosos, cuando a el se unen el lujo y la 
31 MANSILLA, 1996, p. 178-179. É preciso lembrar que a família da autora mantinha ligações antigas com a família de Eugenia, antes mesmo de ela tornar-se imperatriz.

${ }^{32}$ Gilda de Mello e SOUZA, 1987, p. 133-134.

${ }^{33}$ MANSILLA, 1996, p. 178.

34 Patricia FUNES, 1996 , p. 82; e Mónica QUIJADA, 1998, p. 599. elegancia". ${ }^{31}$ Não seriam essas críticas às norte-americanas nesse episódio uma forma de mostrar que aquilo que elas longinquamente vislumbravam como um modelo e uma inspiração era para Mansilla algo muito mais próximo e real? Não seria uma maneira de colocar-se lado a lado com a Imperatriz, num exercício de auto-afirmação de pertencimento a uma linhagem e uma tradição, fazendo jus à sua condição de mulher oriunda de grupos tradicionais da elite argentina?

Há quem questione o local de destaque ocupado pela família da própria Eugenia de Montijo, afirmando que advinha da nobreza decadente espanhola e teria se utilizado das roupas e da moda para conquistar um espaço na corte francesa e forjar destacada ascendência. Assim analisa Gilda de Mello e Souza, quando afirma, ao focalizar a personagem, que "a liderança da moda é um dos meios de que a real parvenue se utiliza para conquistar a admiração de seus súditos" ${ }^{32}$ É possível que Eduarda percebesse essa intenção; caso contrário, não sairia tão veementemente em defesa da imperatriz diante da crença de algumas norte-americanas de que "la condesa de Teba era puramente una mujer cualquiera, recogida en el boulevard por el afortunado autor del Coup d'Ełat". ${ }^{33}$ Assim, além de colocar-se à altura de Eugenia, parecia pretender respaldar a imagem oficial criada por ela sobre sua origem social.

Porém, para além de uma identificação com Eugenia pelo que ela teria de elegante ou tradicional, também podemos levantar outras hipóteses. A primeira delas é a de uma identificação baseada na origem hispânica de Eugenia. Qual hispanidade Mansilla podia estar reivindicando? Apenas aquela relacionada às origens históricas comuns, assinalada pelo fato de advir de uma região colonizada pela Espanha, terra da ex-condessa, então imperatriz? Ou uma hispanidade incorporada como parte da 'latinidade'? Não podemos nos esquecer de que, durante o governo de Napoleão III (1852-1870), esse manifestou pretensões sobre a América de colonização espanhola, apelando a um projeto de unidade dos povos latinos, que era, ao mesmo tempo, uma forma de a França lançar-se sobre a América e barrar as tentativas de expansão dos Estados Unidos (país portador do legado anglo-saxão) sobre o continente americano. Assim, foi fomentada uma dicotomia entre 'latinos' e 'saxões' por meio da qual se afirmava que os primeiros, liderados pela França, eram católicos e portadores de uma "superioridad espiritualista o idealista", contraposta ao protestantismo e a um espírito "pragmático o empirista" dos anglo-saxões. ${ }^{34}$ Essa dicotomia foi usada politicamente para legitimar as pretensões francesas da porção latina do continente americano. Não 
nos parece fortuito o fato de as referências a Eugenia aparecerem justamente nesse relato sobre os Estados Unidos. Seria uma maneira, ainda que indireta, de a autora mostrar adesão a um projeto político.

Há ainda uma terceira e menos clara, mas não descartável, hipótese acerca da identificação entre as duas personagens. Não seria Eugenia para Mansilla uma figura familiar pelo fato de terem ambas colocadas todas as necessárias relativizações, saído das 'margens' e atingido posições extremamente privilegiadas? Além da questionável ascendência nobiliárquica de Eugenia, deve-se lembrar que a Espanha era, no século XIX, considerada o 'Oriente' da Europa, tendo em vista o seu atraso econômico em comparação com nações que se desenvolveram industrialmente, tais como a Inglaterra e a França. Por seu turno, não deve ter sido fácil para Mansilla se livrar da pecha de 'sobrinha de Rosas', o que facilmente era interpretado como traço negativo, tendo em vista o imaginário europeu sobre as repúblicas hispano-americanas, lidas com freqüência como sinônimos de rebeliões, fragmentação territorial, caudilhismo e instabilidades políticas. Eduarda Mansilla e Eugenia de Montijo tinham algo em comum: precisavam reinventar suas origens.

Porém, voltando ao olhar de Eduarda sobre as norteamericanas, pode-se dizer também que fez críticas a um certo exagero na maneira com que as jovens se vestiam e se enfeitavam. A respeito, vale lembrar um trecho em que relata sua passagem pela Filadélfia, local onde teria visto jovens usando um excesso de maquiagem, pintando seus cabelos e comprando muitos perfumes nos boticários. ${ }^{35}$ Da mesma maneira, observa, em outra passagem, ambientada num restaurante de um hotel em Saratoga, jovens usando e abusando da renda e do voal, além da crinolina, utilizada para armar os vestidos:

[...] las ladies estaban todas, sin excepción, vestidas de baile [...] no les faltaban ni encajes, ni joyas, ni mucho ménos flores artificiales en la cabeza [...] [Una joven] ostentaba una profusión de rizos dorados, suyos ó adquiridos a precio de oro, que encuadraban maravillosamente el gracioso óvalo de su cara. Esos rizos eran tan largos, que le llegaban hasta más abajo de la cintura, delgada, muy delgada, y creo ceñida. Vestia un traje de raso azul turquesa, guarnecido de encajes de Aleçon, anchos, como se usaban allá, en los tiempos del Imperio. De trecho en trecho, los volados estaban recogidos por ramilletes de rosas vellosas, blancas. Una anchísima crinolina hacia resaltar los elaborados dibujos de los encajes y la estrechez de la cintura. ${ }^{36}$ 
${ }^{37}$ O estilista é Laferrière (MANSILLA, 1996).

${ }^{38}$ SOUZA, 1987, p. 134 (semelhante idéia é também apresentada nas páginas 116 e 132).

39 MANSILLA, 1996.

${ }^{40}$ MANSILLA, 1996, p. 139.
Para evidenciar o contraste, afirma que, em meio aos exagerados ornamentos, considerou sua roupa um tanto modesta, ainda que assinada por importante e renomado estilista francês. ${ }^{37}$ Novamente parece ter como objetivo assinalar um lugar a si própria, que é diferente e superior àquele em que, em seu discurso, são colocadas as jovens norte-americanas. De certa maneira, Mansilla parece vestir o papel de 'dama exemplar' em oposição à 'arrivista', na diferenciação estabelecida por Gilda de Mello e Souza. Segundo esta autora, no século XIX, a posse de dinheiro pela burguesia emergente possibilita-Ihe copiar a moda e acessar os 'símbolos da vida ociosa'. Entretanto, quando

[...] a arrivista começa a ofuscar a 'dama exemplar' através do luxo dos vestidos [...] uma nova barreira se interpõe entre as classes, ainda mais difícil de transpor que a antiga, pois já não se apóia na ostentação da riqueza, mas no polimento das maneiras, na composição elaborada dos gestos, enfim, no elemento dinâmico da moda. A distinção econômica do luxo cede lugar à distinção estética da elegância. ${ }^{38}$

O luxo, portanto, devia, para Mansilla, ser acompanhado da elegância, e este se contrapunha ao exagero, aos excessos nas vestimentas, às bijuterias. Buscava demonstrar autenticidade e verdadeira filiação a uma linhagem tradicional.

\section{O privado e o público}

Há que se notar que todas essas críticas são lançadas às jovens solteiras, uma vez que pouco teria visto as casadas fora de seus lares. Conforme assinala, as jovens voltavam a pé dos bailes, sempre acompanhadas de seus pais ou pretendentes, enquanto as mães permaneciam em casa. ${ }^{39}$ Segundo a autora, as jovens solteiras tinham grande liberdade, diferente das mulheres casadas, sobretudo as mães de família. Com esse argumento, Mansilla explica o costume das mulheres norte-americanas de se casarem tarde: "Las muchachas norte americanas no tienen prisa por casarse. Prefieren hacerlo tarde, disfrutando, según dicen, su libertad. No les falta razón; pues si son conquetas y flirt como nadie cuando son solteras, así que se casan, dejan de serlo [...]".$^{40}$ Disso também resulta o fato de a autora notar a ausência de mulheres casadas e mães de família nos ambientes de convívio social fora dos lares:

La respuesta obligatoria de toda mujer a quien Vd. le pregunta por su mamá, es: She is an invalid (es enferma). Declaro que, salvo en los viajes y en los hoteles, nunca he visto las madres de los Estados Unidos. 
${ }^{41}$ MANSILLA, 1996, p. 166-167.

42 MANSILLA, 1996, p. 186.

${ }^{43}$ MANSILLA, 1996, p. 189.

${ }^{44}$ MANSILLA, 1996, p. 186.

${ }^{45}$ MANSILLA, 1996, p. 186.

${ }^{46}$ Michelle PERROT, 1989, p. 14.
Parece que la Yankee, así que envejece, se retira voluntaria ó forzosamente de la sociedad. ${ }^{41}$

Se isso parece uma crítica ao hábito de reclusão doméstica da mulher, será justamente no lar, no seio da família, que encontrará o modelo ideal de mulher. Numa visita que fez a uma família amiga de seu cicerone, no Brooklyn, destaca o 'verdadeiro espírito de família' que reinava ali. As mulheres, naquela casa, eram modestas e recatadas. Além disso, assinala a autora: "La madre, allí habia madre, era una bellísima anciana, paralítica, de tez delicada y facciones finas [...]". ${ }^{42}$ É curioso notar que nessa passagem Mansilla também se lembra de sua própria mãe. Na conversa que teve com o chefe da família, Duncan, um almirante, descobriu que, em uma de suas viagens a Buenos Aires, este conhecera Agustina Rosas, mãe de Mansilla. A autora se sensibiliza com a lembrança: "No pudo expresar el enternecimiento que aquele recuerdo me produjo [...]" ${ }^{43}$ Além da associação, mais evidente, da figura da mulher à da mãe, e desta ao lar, em certa medida, a família do Brooklyn remete a autora ao seu país natal, a sua 'mãe' pátria. Em meio à família Duncan, Mansilla mostra que se sentia confortável, segura, tranqüila e em paz. Ao narrar o pacato recinto familiar, a autora cria algumas oposições que refletem um embate entre universos diferentes por ela freqüentados. O Brooklyn representa o 'espírito de família', aproximando-se do tradicional, do provinciano. As mulheres, ali, são virtuosas e distintas: "Hasta el traje de las muchachas, las famosas amigas de mi cicerone, tenía un sello de sencillez ó provincialismo distinguido, que me ganó desde luego. Nada de fast en el atavio de las Miss Duncan: todo era modesto y armonioso, aunque sin style, ó chic". ${ }^{44}$ Usavam roupas cinzas "sin crinolina ni volados, y sus puños y cuello de hilo lisos también, que se armonizaban perfectamente con su mirar reservado [...]". ${ }^{45}$ Eram, portanto, bem diferentes daquelas que exibiam exageradamente seus tules, rendas e laços.

Se a separação entre o público e o privado, aqui, faz-se evidente, sendo clara a associação entre a mulher e o privado, podemos notar ainda um desdobramento do privado em direção ao íntimo. Mansilla associa o íntimo àquilo que é extremamente particular, ao que deve ser resguardado, não publicizado. Analisando diários de mulheres, Michelle Perrot afirma que, no século XIX, o íntimo era muitas vezes tido como 'indecente', devendo ser censurado. Além disso, a busca pela demarcação do âmbito público, de um lado, e do privado e do íntimo, de outro, transparece nos detalhes do cotidiano: "a roupa de cama, mesa e banho pertence à esfera íntima, o vestuário à esfera pública" ${ }^{46}$ Imbuída dessa 
${ }^{47}$ MANSILLA, 1996.

${ }^{48}$ MANSILLA, 1996, p. 176.

${ }^{49}$ MANSILLA, 1996, p. 180.

50 MANSILLA, 1996, p. 27. noção do íntimo, repreende os costumes das norteamericanas de exporem publicamente espaços de convívio íntimo que deviam ser preservados.

Os hábitos mais tradicionais que encontra nas mulheres da família Duncan contrastam com os costumes de outras mulheres que conheceu em sua viagem. Repudia, por exemplo, o uso de se mostrar, nas noites de recepção, o quarto do casal dono da casa para os convidados. Também critica o hábito de deixar à vista do público os lençóis da cama, evidenciando a intimidade do casal, quando era mais correto, em sua visão, arrumá-la com uma colcha escura para que essa intimidade fosse resguardada. ${ }^{47}$

Seu pudor e sua concepção em relação ao que é íntimo parecem se impor como um obstáculo à adoção de certos hábitos. No já mencionado baile na mansão de um banqueiro de Nova lorque, nega-se a entrar no quarto da dona da casa, onde as damas costumavam se enfeitar antes de se apresentarem no salão principal: "Confieso que no penetré en el dormitorio de Mrs. Phelps: despojándome de mi capa en el hall la abandoné á su suerte, en poder de una de las negritas, que me aseguró tendría de ella great care [...]". ${ }^{48}$ Ainda observa criticamente que, em algumas cerimônias, por falta de espaço as donas de casa cediam seus aposentos aos convidados: "Algunas veces he tenido lástima a las opulentas dueñas de casa que cedian así su apoesnto, el aposento en que iban después a descansar, a esa alegre turba danzante. Y no há dejado de sorprenderme no les ocurriera tener um sitio ad hoc". ${ }^{49}$

Finalmente, na parte em que narra seu desembarque em Nova lorque, repara em algumas jovens que, ao receberem e saudarem seus parentes - pais, irmãos e primos -, davam-lhes um aperto de mão e um beijo na boca. Diante da surpresa da cena, a autora se diz tomada por um acesso de riso. Momentaneamente parece reconhecer o 'erro', "hice mal, pero lo hice", mas logo opta por defender os 'seus' valores: "Los lábios me parecen sitio sagrado, que no deben así no más prestarse a públicas efusiones de familia. Si me equivoco, tanto peor, conservo mi error, porque me es grato". ${ }^{50}$

Essa concepção tão marcada pela necessidade do decoro, do resguardo e da contenção repercute em outras várias temáticas tratadas pela autora. Em algumas delas observamos um forte exercício de autocensura em sua narração. Quanto mais 'socialmente condenável' o tema tratado, maior é o veto imposto à própria abordagem. $O$ mais característico exemplo dessa auto-repressão narrativa se localiza na exposição em relação à questão do aborto. Mansilla aborda o assunto de forma tão cifrada que quase não nos deixa perceber exatamente de que tema está 
${ }^{51}$ MANSILLA, 1996, p. 142.

52 De acordo com Néia Schor e Augusta Alvarenga, "Sócrates aconselhava às parteiras, por sinal profissão de sua mãe, que facilitassem o aborto às mulheres que assim o desejassem" (ALVARENGA e SCHOR, 1994).
${ }^{53}$ Peter GAY, 1988, p. 187. tratando. Ao narrar um passeio pela Quinta Avenida, diz avistar uma casa misteriosa:

\begin{abstract}
verdad es que a cierta altura de la famosa calle, el viajero se encuentra con la suntuosa habitación de madame $\mathrm{T}[. .$.$] y que al preguntar quién es esa riquísima$ propietaria, una sonrisa fisgona contrae los semblantes masculinos. Pero, cómo evitar que una mujer que practica el oficio de la madre de Sócrates haga fortuna en esa tierra clásica de las libertades? A mí, ademas, no me importa el cómo, ni quiero escuchar lo que de ella se cuenta; a ser verdad, fuera demasiado horrible: y me guardaré bien de escribirlo. Basta y sobra con haber encontrado en mi camino ese misterioso palacio, cuyo recuerdo me pesa. ${ }^{51}$
\end{abstract}

Não fosse a referência à "mãe de Sócrates", seria praticamente impossível descobrir que se tratava de uma casa dedicada à realização de abortos. ${ }^{52} \mathrm{~A}$ despeito da forma enviesada com que trata o assunto, o fato de mencionar o aborto não é de todo estranha, sobretudo se pensarmos que essa medida - ao lado da contracepção estava sendo cada vez mais praticada, justamente nos Estados Unidos de meados do século XIX, como demonstra o historiador Peter Gay. Segundo o autor, apesar de condenada pela Igreja, cuja moral associava a relação sexual estritamente à reprodução, a contracepção era assunto embaraçoso, mas inevitável no século XIX. O aborto, por sua vez, ganhava força como 'segunda manobra defensiva', usada pelos casais que haviam falhado na contracepção e que queriam evitar as famílias muito numerosas:

O aborto, essa segunda manobra defensiva, tão drástica e perigosa que geralmente era empregada apenas quando a anticoncepção havia falhado, veio a tornar-se praticamente moda nos Estados Unidos por volta do meio do século [...] Diversas pesquisas levadas a cabo nos Estados Unidos, realizadas sobretudo por associações médicas locais, confirmaram que as mulheres americanas se voltavam para o aborto não somente para destruir os resultados indesejados de um mau passo ilícito, como também para controlar o tamanho de suas famílias legítimas. ${ }^{53}$

Além disso, também é significativo o fato de Mansilla designar a casa como um "palácio" de uma "rica proprietária" da Quinta Avenida. Segundo Peter Gay, a condenação oficial do aborto tendeu a limitá-lo precisamente aos setores mais abastados da população:

Se bem que tanto nos Estados Unidos quanto noutras partes do mundo o aborto não fosse uma prerrogativa 
${ }^{54}$ GAY, 1988, p. 188.

${ }^{55}$ David VIÑAS, 1998, p. 82. exclusiva da classe média, a expansão da legislação antiaborto a partir da década de $1860 \mathrm{fez} \mathrm{com}$ que os preços cobrados pela sua prática aumentassem muito, reservando-o cada vez mais às famílias mais prósperas e abastadas. ${ }^{54}$

Ao refletir sobre a maneira indireta pela qual Mansilla aborda a temática, o crítico literário e escritor argentino David Viñas aponta que seus limites estavam, em grande medida, assinalados pela questão de classe. Assim, afirma que a autora se expressa de acordo com os "términos de su conciencia posible, el borde donde asoma su autocensura calcada sobre las presiones sociales de la clase a la que pertence". ${ }^{55}$ Os contrastes são óbvios: de um lado a matriarca e as filhas da família Duncan encerradas no lar, no âmbito privado; de outro, figuram 'mulheres públicas', de vida mundana, que para a autora viviam 'ao lado do pecado'.

Há, contudo, para Mansilla, formas 'mais respeitáveis' de se fazer parte do público. Um dos exemplos pode ser notado quando se põe a descrever a dedicação das mulheres norte-americanas ao periodismo feminino. A admiração ao trabalho das repórteres norte-americanas não se dá, entretanto, sem ressalvas. Faz questão de assinalar que $o$ tipo de periodismo comumente praticado pelas mulheres dos Estados Unidos nada tinha de masculino. Ao contrário, elas tratavam de assuntos amenos, como o colunismo social, a moda e uma literatura "ingênua" e "saudável", que eram descartados pelos homens por considerá-los pouco varonis. Se, por um lado, procura apaziguar um efeito supostamente transgressor em sua demonstração de admiração pelo trabalho feminino, por outro faz questão de não banalizar a atividade das escritoras, afirmando que, a despeito da amenidade dos temas, estes eram tratados com conhecimento e profundidade. Por esse meio de atuação, afirma Mansilla,

Las mujeres influyen en la cosa pública por medios que llamaré psicológicos e indirectos.

En el periodismo, véseles ocupando de frente un puesto que nada de anti-femenino tiene. Los periódicos en los Estados Unidos, el país más rico en publicaciones de ese género, cuentan con una falanje que representa para ellos el elemento ameno. Mujeres son las encargadas de los artículos de los Domingos, de esa literatura sencilla y sana, que debe servir de alimento intelectual a los habitantes de la Union, en el dia consagrado a la meditación.

Son ellas también las que, por lo general, traducen del aleman, del italiano y aún del francés, los primeros capítulos de los nuevos libros, con que el periódico engalana sus columnas; ellas las que dan cuenta cabal y exacta de las fiestas, cuyos detalles finísimos y 
${ }^{56}$ MANSILLA, 1996, p. 120-121.

${ }^{57}$ MANSILLA, 1996, p. 121.

${ }^{58}$ MANSILLA, 1996, p. 140.

59 GARCÍA-MANSILLA, 1950. acabados llevan el sello del connaisseur. Reporters femeninos, son los que describen con amore el color de los trajes de las damas, su corte, sus bellezas, sus misterios, sus defectos; y á fe que lo hacen concienzuda y científicamente. ${ }^{56}$

Além disso, pensa que esse tipo de trabalho abria possibilidades para que as mulheres buscassem por si próprias os meios para sua sobrevivência. Desta maneira, a autora mostra-se preocupada com a questão da dependência financeira das mulheres e de suas limitações às atividades domésticas:

En ello ademas, las mujeres tienen un medio honrado é intelectual para ganar su vida: y se emancipan así de la cruel servidumbre de la aguja, servidumbre terrible desde la invencion de las máquinas de coser. Mas tarde debia aparecer la mujer empleado, ya en el Correo ya en los Ministerios.

Una buena reporter gana en los Estados Unidos de dosciento cincuenta a trescientos duros mensuales. ${ }^{57}$

Outro tema 'proibido' enfocado no relato é o divórcio. Mansilla procura mostrar que as norte-americanas divorciadas não eram moralmente condenadas pela sociedade. Entretanto, evitando que seu comentário denotasse qualquer tipo de opinião extremada, faz a ressalva de que o divórcio, nos Estados Unidos, era um recurso adotado apenas em casos de extrema necessidade e não uma prática banal:

Los norte americanos tienen el recurso del divorcio, del cual no abusan, pero sí usan. Yo he conocido varias damas muy distinguidas, que, despues de dovorciadas de su primer marido, por causas que ignoro, habian contraido matrimonio con el Master tal, bajo cuyo nombre yo las conocí, sin desmerecer por eso en la sociedad. Pero, lo repito, usan, no abusan, de tal recurso. ${ }^{58}$

Ainda que relate fatos vividos na década de 1860 , quando ainda era recém-casada, o texto foi publicado no início da década de 1880, quando se encontrava em Buenos Aires, separada do marido, sendo possível, assim, algum paralelismo entre a escolha do tema e sua situação pessoal. Depois do casamento de sua filha, Eda, em 1875, Eduarda retornou sem o marido para Buenos Aires. Daniel Mansilla, que em seu livro de memórias traça em detalhes aspectos da vida da mãe, passa por cima desse episódio, narrando apenas o posterior retorno da mãe de Buenos Aires à Europa. ${ }^{59}$ De acordo com María Rosa Lojo, "esta opción, que significó dejar a sus hijos menores en manos de la hija mayor, ya casada, implicó una dura crítica social (quizá en particular, la de las mujeres que no pensaban como ella) y 
${ }^{60}$ LOJO, 1999a, p. 27.

${ }^{61}$ MANSILLA, 1996, p. 61-63. concluyó a su regreso con su matrimonio y su vida familiar". ${ }^{60}$ Existam ou não relações diretas entre aspectos de sua vida pessoal e a abordagem do divórcio, o fato é que, além de manter absoluto silêncio sobre seu marido ao longo de todo o relato, resguardando, assim, sua privacidade, o tema é tratado com muitas reservas de modo a não dar margem a uma idéia de total engajamento em relação a essa causa. Seu intuito é mostrar que o divórcio não pode se dar por causas banais e que é possível a uma mulher se divorciar e manter seu status social.

Finalmente, além das idéias em relação ao divórcio, ao aborto e à ocupação profissional das mulheres, discorre em alguns momentos sobre a política, considerada, no século XIX, 'assunto sério' e reservado aos homens. Mansilla faz, por exemplo, duras críticas à forma como o governo expropriou os indígenas no processo de ocupação territorial dos Estados Unidos.

Dolorosa es la historia que llamaré privada de los Estados Unidos, en conctato con esas tríbus salvajes que poblaban los territoriso de Nevada, Colorado, etc. Así que el Yankee tuvo una existencia política asegurada, no se contentó ya con comprar, como en otro tiempo, tierras a los indígenas, decidió destruir la raza por todos los medios a su alcance. Muerte, traición y rapiña han sido las armas con las cuales los han combatido; promesas y engaños, he ahí su política con los hijos del desierto. [...] Más de una vez he oído algunos hijos de la Union, de corazon generoso, deplorar tan terribles abusos [...]. Cuando he visto caciques Rojos, sentados á la mesa del Presidente de los Estados Unidos, en esa actitud reservada y digna, acompañada de un mirar melancólico y profundo, tan penetrante, he sentido respeto y enternecimiento por los descendientes de los dueños de la tierra, que hoy ocupa la Union, despojados, desdeñados, enganados por los hombres que profesan una religion de igualdad y mansedumbre, y que, sin embargo, no practican el principal de los preceptos: la fraternidad. No se me acuse de sentimentalismo, ó mejor dicho, écheseme en cara el sentir, no me será disgustoso. ${ }^{61}$

É curioso notar que a autora não faz nenhuma menção ao processo de ocupação do território argentino na segunda metade do século XIX. A chamada 'Campanha do Deserto' cujo maior expoente foi o general Julio A. Roca, ministro de Guerra e Marinha em 1879 e Presidente da República em 1880 - foi movida sob pretexto da instauração de um projeto de colonização agrícola com emprego de mão-de-obra européia que implicava a ocupação e o povoamento das terras ainda desabitadas ou das ocupadas pelos índios. As violentas campanhas contra os índios, considerados pelos 
62 Sobre esse tema, ver Gabriel PASSETTI, 2005.
${ }^{63}$ Nicolas SHUMWAY, 1993, p. 279. liberais como entraves para o progresso, resultaram no seu extermínio. ${ }^{62}$ Ainda que a questão indígena tenha se intensificado no fim da década de 1870 , sob a liderança de Roca, anteriormente outros governos já haviam tentado levar adiante negociações e tratados com os índios. Na realidade, na década de 1830, Juan Manuel de Rosas já movera uma primeira campanha liberando uma quantidade significativa de terras sob domínio indígena. Uma retomada mais sistemática, pelos liberais, só se daria após o término da Guerra do Paraguai, ganhando certo fôlego no governo de Sarmiento (1868-1874). Não podemos deixar de lembrar aqui que, durante esse governo, mais precisamente em finais de 1868 , o general Lucio Mansilla, irmão de Eduarda, foi designado por Sarmiento para estabelecer negociações, na Província de Córdoba, com caciques da etnia ranquel. A experiência resultou na publicação de um relato inicialmente veiculado em forma de folhetim no periódico porteño La Tribuna e posteriormente publicado em forma de livro sob o título Una excursión a los indios ranqueles. Segundo o crítico literário Nicolas Shumway, Lucio Mansilla representou uma exceção entre os homens de sua geração no que se referia à concepção em relação à forma de tratamento que deveria ser reservada aos índios. Os liberais, em sua grande parte, viam "con aprobación tácita o expresa la guerra al indio. Una interesante y parcial excepción a este consenso, sin embargo, es Lucio V. Mansilla [...]".63

Diante disso, ainda que não se possa afirmar categoricamente, é possível supor que Eduarda Mansilla, que publicou seu relato em 1882, portanto, poucos anos após a campanha vitoriosa de Roca sobre os índios, estivesse, com suas observações críticas à política indígena adotada pelo governo norte-americano, espelhando, ainda que indiretamente, o processo de conquista das fronteiras indígenas em seu próprio país.

Dentre as temáticas 'proibidas' é na questão política que seu relato atinge maior radicalidade, mas ainda assim percorre caminhos enviesados, pois, no fundo, era muito provavelmente a respeito do extermínio dos indígenas na Argentina - fato praticamente concomitante à publicação de seu relato - que Eduarda queria chamar a atenção. Em vez de dirigir diretamente sua crítica ao governo argentino, utiliza-se do subterfúgio de criticar similar processo histórico ocorrido nos Estados Unidos décadas antes.

\section{Conclusão}

Cabe, para concluir, perguntar como poderíamos ponderar as observações de Mansilla sobre as norteamericanas, observações que no fundo refletiram seus 
${ }^{64}$ SOSA DE NEWTON, 1994, p. 92.

${ }^{65}$ FREDERICK, 1994, p. 249-250.

${ }^{66}$ FREDERICK, 1994, p. 251. próprios valores sobre o comportamento feminino. Suas idéias eram tendentes a uma flexibilização das rígidas normas sociais a que as mulheres de elite estavam submetidas ou simplesmente perpetuavam essas mesmas normas?

Algumas análises sobre a obra de Mansilla, realizadas sobretudo por críticos literários, coincidem na visão de que a autora não questionou ou relativizou certos padrões do comportamento feminino estipulados pelo discurso hegemônico. Por isso lançou mão do decoro, da autocensura e do acatamento a certas normas de respeitabilidade social. Segundo Lily de Sosa, a autora manteve distância das idéias feministas: "Eduarda no pareció advertir ciertos movimientos, inserta como estaba en su micromundo de elegante frivolidad". ${ }^{64}$ Bonnie Frederick, que compara o relato de Eduarda aos de seu irmão Lucio Mansilla, mostra que a viajante, ao levar junto de si os filhos, condiciona os itinerários e as temáticas abordadas a seu papel de mãe:

Los recuerdos de Eduarda nunca salen del ámbito decoroso de las visitas a museos, conciertos, las compras y tomar el té. Observa las intrigas amorosas de otros, pero tiene mucho cuidado en establecer que ella no coquetea nadie [...] Muchos recuerdos de Eduarda tienen que ver con sus niños: la comida y la ropa, las enfermedads, la hora de acostarles, las lecciones de baile, una visita a la casa de moneda, etc. ${ }^{65}$

Além disso, a manutenção de um ideal convencional de feminilidade estaria fortemente vinculada à condição social da autora. O pertencimento a uma família tradicional e da elite de Buenos Aires jogaria um papel importante na delimitação das temáticas abordadas: "su viaje se constituye como una serie de lugares protegidos donde su comportamiento y actividades no son muy diferentes que su vida en Buenos Aires. Su mobilidad y ámbito están limitados por las normas de respectabilidad típicas de su clase". ${ }^{6}$

Como mulher de elite do século XIX, Eduarda Mansilla sofreu pressões em torno do casamento e das demais cobranças sociais em relação a certas normas de respeitabilidade. Esses elementos relacionados ao universo cultural feminino transparecem em seu texto. Evidencia-se nesse relato a força da idéia de que a mulher possuía qualidades essenciais que naturalmente deviam atrelá-la ao âmbito do privado.

A despeito disso, não se pode dizer que acatou integral e passivamente os consagrados 'papéis femininos', a começar por sua própria trajetória como escritora e viajante. Seu texto é atravessado por tensões. Ao mesmo tempo que guarda fortemente as normas e os padrões do discurso dominante, permite-se discorrer sobre 'temas vetados', como o divórcio, o aborto e a atuação profissional 
da mulher, ou sobre os chamados 'assuntos sérios', como a política. Ao não se furtar a abordá-los e ao tratá-los com reserva e cautela, evitando possíveis desdobramentos, mostrou que preferia aderir aos modos 'indiretos' de exercer influência no público.

\section{Referências bibliográficas}

ALVARENGA, Augusta; SCHOR, Néia. "O aborto: um resgate histórico e outros dados". Revista Brasileira de Crescimento e Desenvolvimento Humano, São Paulo, v. 4, n. 2, 1994.

AUZA, Nestor Tomás. La literatura periodistica porteña del siglo XIX: de Caseros a la Organización Nacional. Buenos Aires: Editorial Confluencia, 1999.

BATTICUORE, Graciella; ZUCCOITI, Liliana. "Papeles de entrecasa. Juana Manuela Gorriti". In: XX INTERNATIONAL CONGRESS. LATIN AMERICAN STUDIES ASSOCIATION, 1997, Guadalajara, México.

FRANCO, Stella Maris Scatena. Peregrinas de outrora: viajantes latino-americanas no século XIX. Florianópolis: Editoras Mulheres; Santa Cruz do Sul: Edunisc, 2008.

FREDERICK, Bonnie. "El viajero y la nómada". In: FLETCHER, Lea (Org.). Mujeres y cultura en la Argentina del siglo XIX. Buenos Aires: Feminaria, 1994.

FUNES, Patrícia. "Del mundus novus al novomundismo. Algunas reflexiones sobre el nombre de América Latina". In: DAYRELL, Eliane Garcindo; IOKOI, Zilda Gricoli (Org.). América Latina contemporânea: desafios e perspectivas. São Paulo: Edusp; Rio de Janeiro: Expressão e Cultura, 1996.

GARCÍA-MANSILLA, Daniel. Visto, oído y recordado: apuntes de un diplomata argentino. Buenos Aires: Editorial Guillermo Kraft, 1950.

GAY, Peter. A experiência burguesa da Rainha Vitória a Freud: a educação dos sentidos. São Paulo: Companhia das Letras, 1988.

LOJO, María Rosa. "'El género mujer' y la construcción de mitos nacionales: el caso argentino rioplatense". In: ARANCIBIA, Juana Alcira (Dir.). La mujer en la literatura del mundo hispánico. California: Instituto Literário y Cultural Hispánico, 1999a. v. V.

. "Naturaleza y ciudad en la novelística de Eduarda Mansilla. In: NAVASCUÉS, Javier de (Ed.). De Arcadia a Babel. Naturaleza y ciudad en la literatura hispanoamericana. Madrid: Iberoamericana; Frankfurt: Vervuert, 2002.

MANSILLA, Eduarda. Recuerdos de viaje. Madrid: Ediciones El Viso, 1996.

. Pablo o la vida en las Pampas. Buenos Aires: Editorial Confluencia, 1999. 
MANSILLA, Lucio V. Mis memorias. Buenos Aires: El Ateneo Editorial, 1978.

MIZRAJE, María Gabriela. Argentinas de Rosas a Perón. Buenos Aires: Biblos, 1999.

PASSETTI, Gabriel. Indígenas e criollos: política, guerra e traição nas lutas no sul da Argentina (1852-1885). Dissertação (Mestrado em História) " Faculdade de Filosofia, Letras e Ciências Humanas, Departamento de História, Universidade de São Paulo, 2005. Mimeografado.

PERROT, Michelle. "Práticas da memória feminina". Revista Brasileira de História, São Paulo, v. 9, n. 18, 1989.

QUIJADA, Mónica. "Sobre el origen y difusión del nombre 'América Latina' (o una variación heterodoxa en torno al tema de la construcción social de la verdad)". Revista de Indias, Espanha: CSIC, v. LVIII, n. 214, 1998.

ROMERO, José Luis. Las ideas en la Argentina del siglo XX. Buenos Aires: Biblioteca Actual, 1987.

SCOBIE, James. R. La lucha por la consolidación de la nacionalidad argentina. 1852-1862. Buenos Aires: Hachette, 1964.

SHUMWAY, Nicolas. La invención de la Argentina. Historia de una idea. Buenos Aires: Emecé, 1993.

SOSA DE NEWTON, Lily. "Eduarda Mansilla de García: narradora, periodista, música y primera autora de literatura infantil". In: FLETCHER, Lea (Org.). Mujeres y cultura en la Argentina del siglo XIX. Buenos Aires: Feminaria, 1994.

SOUZA, Gilda de Mello e. O espírito das roupas: a moda no século dezenove. São Paulo: Companhia das Letras, 1987.

SZURMUK, Mónica. Mujeres en viaje. Escritos y testimonios. Buenos Aires: Alfaguara, 2000.

VIÑAS, David. De Sarmiento a Dios. Viajeros argentinos a USA. Buenos Aires: Editorial Sudamericana, 1998.

[Recebido em setembro de 2008 e aceito para publicação em outubro de 2008]

\footnotetext{
An Argentinean Lady in Yankee Land. The Travel Memoirs of Eduarda Mansilla

Abstract: In this article I analyze the account of a journey the Argentinean writer Eduarda Mansilla made to the United States, which she called Travel Memoirs (1882). Eduarda Mansilla was part of a privileged social class and came from a traditional family belonging to the political elite in Argentina, she exposed a particular point of view on the behavior of the North Americans who she lived with during her travel, unveiling her own conceptions on female social roles.
}

Key Words: Journey Account; Women; Eduarda Mansilla. 